\title{
Problematizando o trabalho invisível das mulheres e a divisão sexual de trabalho no campo: uma parceria entre educação popular e feminismo
}

\author{
Carla Negretto ${ }^{1}$, Márcia Alves da Silva ${ }^{2}$ \\ ${ }^{1}$ Universidade Federal de Pelotas - UFPEL. Centro de Sociais Aplicadas e Humanas. Campus ICH ISP FAE. Rua \\ Coronel Alberto Rosa, 154. Centro. Pelotas - RS. Brasil. ${ }^{2}$ Universidade Federal de Pelotas - UFPEL. \\ Autor para correspondência/Author for correspondence: ka_karllynha10@hotmail.com
}

\begin{abstract}
RESUMO. Historicamente, as mulheres camponesas, assim como as mulheres urbanas, sofrem com a desigualdade de gênero. Desse modo, o sistema patriarcal que reforça a divisão sexual do trabalho resume a vida de muitas mulheres, tanto à dominação e exploração quanto à responsabilidade única pelos afazeres domésticos e pelo cuidado com os filhos. Esse artigo desenvolve algumas reflexões que se referem a uma experiência investigativa que a autora vem desenvolvendo desde o ano de 2014 com mulheres assentadas da Reforma Agrária e que tem como objetivo problematizar as relações de gênero e poder ligadas à divisão sexual do trabalho entre homens e mulheres de 2 assentamentos da Reforma Agrária localizados no interior do município de Pinheiro Machado/RS. Pretende-se explorar o espaço social e as experiências de vida, dando voz as mulheres sobre suas trajetórias de vida e trabalho, debatendo juntamente com o público masculino aspectos da reprodução social que divide atribuições, tarefas e lugares para homens e mulheres. Para finalidade dessa proposta, essa pesquisa participativa atenta para os métodos da Educação Popular e os estudos Feministas que possibilitem momentos dinâmicos e modificáveis dirigidos para uma transformação social.
\end{abstract}

Palavras-chave: Relações de Gênero, Mulheres, Trabalho, Educação Popular, Feminismo. 


\title{
Problem the invisible work of women and the sexual division of work in the field: a partnership between popular education and feminism
}

\begin{abstract}
Historically, peasant women, as well as urban women, suffer from gender inequality. Thus the patriarchal system that reinforces the sexual division of labor sums up the lives of many women, both domination and exploitation, and the sole responsibility for household chores and childcare. This article develops some reflections that refer to an investigative experience that the author has been developing since the year 2014 with women based on Agrarian Reform and whose objective is to problematize gender and power relations related to the sexual division of labor between men and women of 2 settlements of Agrarian Reform located in the interior of the municipality of Pinheiro Machado/RS. It is intended to explore social space and life experiences, giving women voice on their life and work trajectories, discussing with the male public aspects of social reproduction that divides assignments, tasks and places for men and women. For the purpose of this proposal, this participatory research attentive to the methods of Popular Education and Feminist studies that allow dynamic and modifiable moments directed towards a social transformation.
\end{abstract}

Keywords: Gender, Women, Labor, Popular Education, Feminism. 


\section{Problematizando el trabajo invisible de las mujeres y la división sexual de trabajo en el campo: una asociación entre educación popular y feminismo}

RESUMEN. Históricamente, las mujeres campesinas, así como las mujeres urbanas, sufren con la desigualdad de género. De este modo, el sistema patriarcal que refuerza la división sexual del trabajo resume la vida de muchas mujeres, tanto a la dominación y explotación como a la responsabilidad única por los quehaceres domésticos y por el cuidado con los hijos. Este artículo desarrolla algunas reflexiones que se refieren a una experiencia investigativa que la autora viene desarrollando desde el año 2014 con mujeres asentadas de la Reforma Agraria $\mathrm{y}$ que tiene como objetivo problematizar las relaciones de género y poder ligadas a la división sexual del trabajo entre hombres y mujeres de 2 asentamientos de la Reforma Agraria ubicados en el interior del municipio de Pinheiro Machado / RS. Se pretende explorar el espacio social y las experiencias de vida, dando voz a las mujeres sobre sus trayectorias de vida y trabajo, debatiendo junto con el público masculino aspectos de la reproducción social que divide atribuciones, tareas y lugares para hombres y mujeres. Para fines de esta propuesta, esa investigación participativa atenta para los métodos de la Educación Popular y los estudios Feministas que posibiliten momentos dinámicos y modificables dirigidos hacia una transformación social.

Palabras clave: Relaciones de Género, Mujeres, Trabajo, Educación Popular, Feminismo. 


\section{Introdução}

Este trabalho apresenta e problematiza as relações de gênero ligadas a divisão sexual do trabalho entre homens e mulheres dos assentamentos Alegrias e Santa Inácia, localizados na zona rural do município de Pinheiro Machado/RS. Para atender as finalidades dessa proposta, a pesquisa vem aproximando a metodologia da educação popular com os estudos da teoria feminista, numa práxis que segundo Paulo Freire, possibilite a relação entre humanização e educação, valorizando os saberes e a realidade do povo para construção de novos saberes com metodologias incentivadoras a participação e ao empoderamento desses sujeitos(as), permeado por um processo de construção de conhecimento pedagógico e político, estimulador de transformação social, liberdade e felicidade.

É importante salientar que a pesquisa também agrega dados já coletados de um Projeto de Extensão da Universidade Federal de Pelotas, denominado "Trabalho Artesanal com Mulheres do Movimento de Trabalhadores Rurais Sem Terra (MST)”, do qual a pesquisadora fez parte como bolsista ministrante e membro da comissão organizadora, desenvolvendo atividades ligadas a confecção artesanal, gênero e educação nos anos de 2014 a 2016 com 4 grupos de mulheres pertencentes aos assentamentos: Alegrias, Campo Bonito, Pinheiro Machado e Santa Inácia, todos localizados no município de Pinheiro Machado/RS. Os dados coletados durante o período, estão sendo analisados buscando não apenas descrever, como ocorre a divisão sexual do trabalho no campo, mas também indagando respostas num empenho coletivo com os participantes (homens e mulheres) para interromper os processos históricos do sistema patriarcal. Com base no diálogo entre Educação Popular e os estudos feministas, a pesquisa reflexiona questões pertinentes sobre o papel da mulher na sociedade, fazendo um resgate histórico com esses sujeitos sobre a participação feminina no desenvolvimento dos processos de produção e reprodução da força de trabalho, marcado pela exclusão e pela inviabilização. Promover a reflexão sobre esses aspectos, é parte dessa proposta metodológica, que busca trabalhar a consciência de que é preciso mudar as relações que qualificam e redimensionam a tripla jornada de trabalho feminino no campo, inteirando esse paradigma cultural como um componente das relações sociais no modelo capitalista patriarcal.

\section{Metodologia}

\begin{tabular}{|l|l|l|l|l|l|l|l|} 
Rev. Bras. Educ. Camp. & Tocantinópolis & v. 3 & n. 4 & p. 1184-1201 & set./dez. & 2018 & ISSN: 2525-4863
\end{tabular} 
Discutir questões sobre gênero, trabalho e empoderamento feminino no meio rural, exige que a pesquisa utilize uma metodologia participativa que possibilite um trabalho popular de dimensão pedagógica e política, dirigido à transformação social. Para atender o objetivo proposto dessa pesquisa-ação, de problematizar as relações de gênero e poder ligadas a divisão sexual do trabalho entre homens e mulheres assentados da reforma agrária do município de Pinheiro Machado/RS, materializamos esse processo partindo da realidade concreta dos participantes, compreendendo as especificidades da realidade local em suas diferentes dimensões e interações. A coleta de dados sobre a realidade de vida e trabalho no cotidiano rural, contempla observação participante, "rodas de conversa", anotações em um diário de campo, oficinas artesanais e fotografias. Estas ferramentas metodológicas tem um fundamento pedagógico e político que possibilita um pensar dialógico e critico a respeito da realidade social.

A proposta dos encontros dialógicos, por meio das rodas de conversa, realizado antes da confecção artesanal como demonstra a figura abaixo, nos oferece a oportunidade de discutir as atribuições dos distintos papéis delegados as diferentes categorias de sexo. Esses papéis foram construídos sobre o mito da superioridade masculina, criando assim uma estrutura que domina, reprime e subordina a mulher. Problematizar e refletir coletivamente com esses sujeitos como foram construídas as relações de gênero, nos abre possibilidades para questionar as relações de poder e indagar respostas sobre "a quem serve a relação de dominação da mulher pelo homem" (Saffioti, 1987, p. 21).

Figura 1 - Encontro dialógicos (rodas de conversa) realizado com homens e mulheres do Assentamento Alegrias, município de Pinheiro Machado/ RS. 


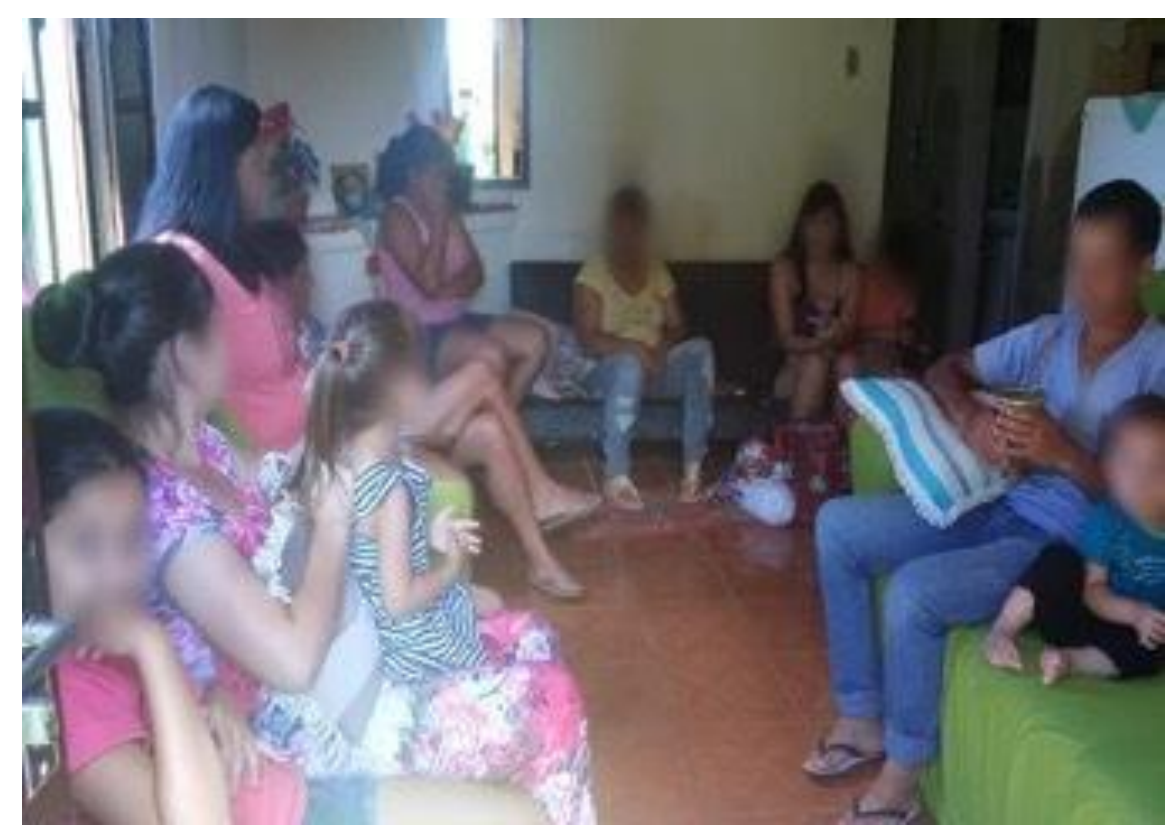

Fonte: Projeto "Trabalho Artesanal com Mulheres do movimento dos Trabalhadores Rurais Sem Terra”, jan., 2016.

Nessa construção dialógica, levamos em conta a pertinência dos relatos trazidos pelos participantes (homens e mulheres) sobre as atribuições de distintos papéis delegado às diferentes categorias de sexo. É o diálogo sobre esse cotidiano que desmascara a naturalização de papéis sociais e muda o conceito sobre a divisão sexual do trabalho e a compreensão do que é opressão. Essa forma dialógica de educar, com base na realidade das pessoas participantes, com elas e não para elas,

Visa à libertação do ser humano, ao atuar contra os efeitos de uma psicologia da opressão, por meio de um processo de conscientização de sujeitos ativos - isto é, políticos -, portanto, capazes de se organizar e transformar, eticamente, a história que está sendo construída permanentemente por seres humanos (Vieira, 2012, p. 163).

Figura 2 - Grupo de mulheres e homens nas 'rodas de conversa' - realizando um diálogo sobre o cotidiano rural. Assentamento Alegrias, Pinheiro Machado/RS. 


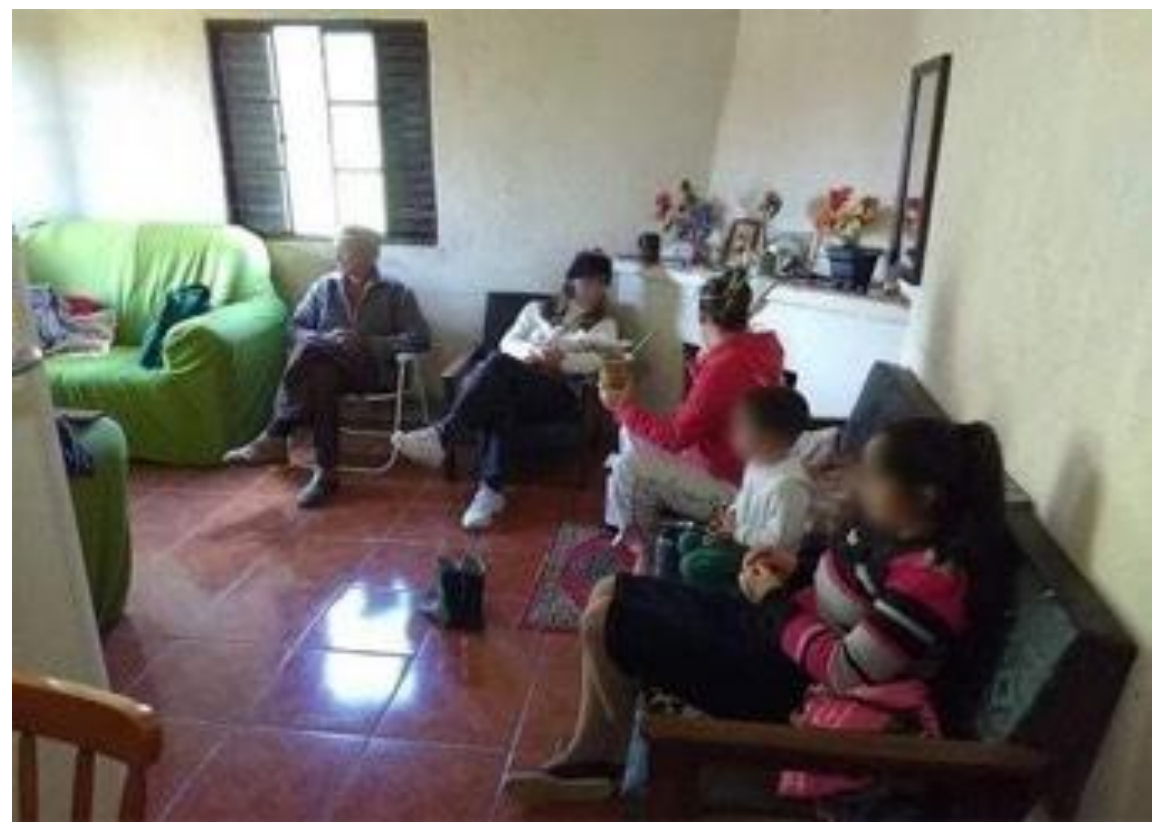

Fonte: Acervo de Pesquisa, out., 2017.

A função social que é delegada à mulher camponesa, na reprodução e perpetuação dos papéis sócio-familiares historicamente constituídos, na maioria das vezes as afasta das decisões importantes dentro da propriedade e comunidade. Ao tentarem transpor essas barreiras, enfrentam ainda mais dificuldade, é o que relata uma das participantes: "Há dias que meu pai não deixa de jeito nenhum minha mãe vir comigo para as oficinas, ele diz que ela tem que ajudá-lo na lavoura e ponto final. Se eu ficar esperando demais por ela, acabo eu não participando" (Assentada A, 2016). Ao analisarmos esses depoimentos, observamos nitidamente o sistema patriarcal se fazendo vigente. São esses alaridos, trazidos para dentro das rodas de conversa que a pesquisa busca analisar e consequentemente trabalhar para romper com esse sistema hierárquico que domina a vida de muitas mulheres. É nesse contexto que a educação popular feminista entra em ação, transmutando os relatos da vida cotidiana, apresentadas nas rodas de conversa, em pautas de luta feminista pelo direito da equidade entre os gêneros, direito a ter voz nos espaços de decisão, direito à participação econômica nos lucros e direito à felicidade plena.

A proposta das oficinas artesanais como revela a imagem abaixo, compreende uma segunda atribuição significativa para a investigação. Elas são usadas como ferramenta metodológica para reintegração do grupo dando suporte para a valorização dos saberes, do trabalho e da luta feminina. É nas relações intrínsecas das rodas de conversa, nas texturas, entre as sucatas, os tecidos e as agulhas que mais relatos sobre 
a 'vida vivida' são trazidos à tona com forte significado pessoal. Através dessa memória rememorada,

entrelaçamos passado, presente e futuro, pois é olhando o passado que conseguimos compreender as cicatrizes da opressão, medo e silêncio que a vida feminina é levada no paradigma sociocultural a vivenciar. É através da vida vivida que cada mulher reinterpreta os fatos do outrora no presente, dando-lhes novos significados se assim julgar oportuno (Negretto \& Silva, 2017, p. 2216-2217).

Figura 3 - Oficina artesanal com o grupo de mulheres do Assentamento Santa Inácia, município de Pinheiro Machado/RS.

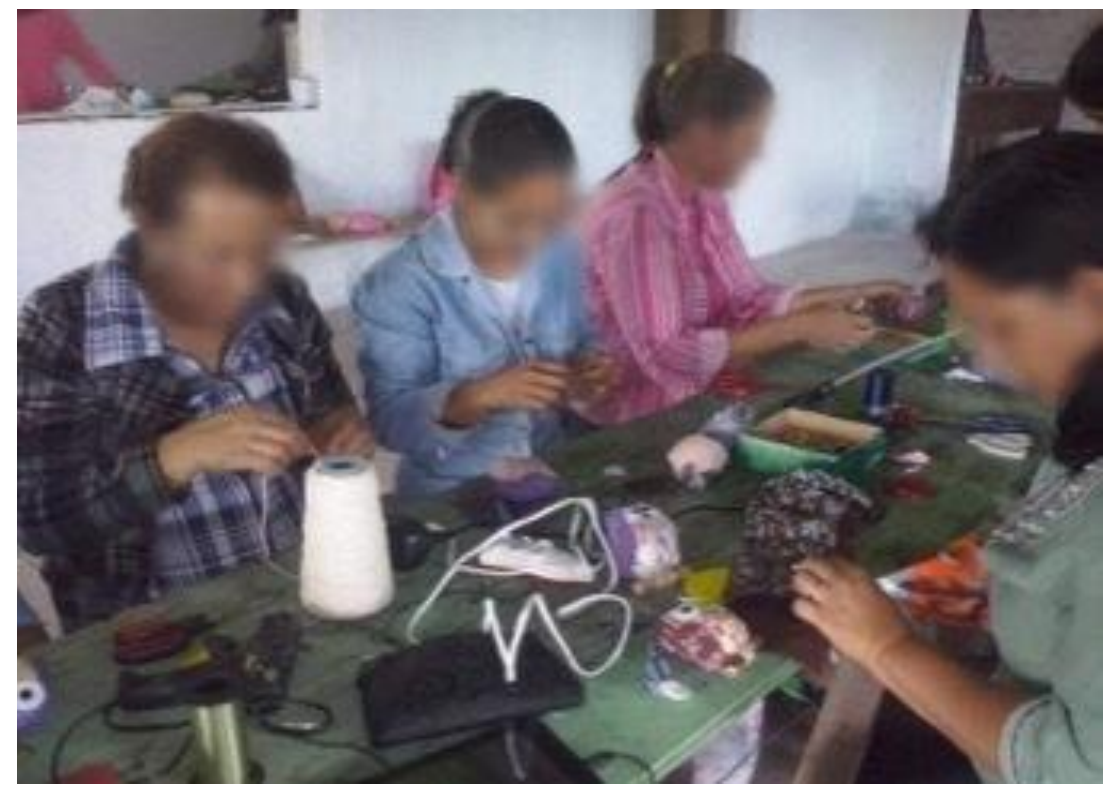

Fonte: do projeto, maio de 2015.

Esta abordagem metodológica, nos têm permitido interpretar as fases da vida do homem e da mulher rural. Suas experiências experimentadas de forma individual ou coletiva, nos trazem possibilidades concretas para compreender como ocorrem as relações de gênero e a divisão sexual do trabalho dentro e fora dos assentamento. A intenção política pedagógica aqui, é fazer com que os sujeitos se percebam, autores de suas próprias vidas, explicitando em parceria com os estudos feminista toda a acumulação primitiva que domesticou mulheres e homens e redefiniu o conceito de feminilidade e masculinidade.

Problematizar as trajetórias de vida e trabalho abre possibilidades para construção de novos horizontes e questionamentos críticos sobre os papéis sociais atribuídos aos sexos. A organização de encontros e oficinas artesanais se 
concretizam em ferramentas possibilitadoras de libertação, visto que, é por meio desses espaços que muitas mulheres tem a oportunidade de se desprender das regras de conduta social, podendo construir uma nova identidade pessoal.

Ao ser induzida como influente ferramenta metodológica para a abordagem do universo feminino, as oficinas artesanais se materializam em espaços de construção coletiva e trocas de experiências de vida, onde o saber/fazer artesanato é reconhecido como trabalho feminino e não como algo 'menor', isso porque, para muitas participantes, ele assegura geração de renda.

Grande parte das oficinas, são realizadas nas sedes dos assentamentos. Quando não é possível dispor desses ambientes, ocupamos os espaços disponíveis nas residências das participantes, ou organizamos oficinas artesanais ao ar livre. As matérias-primas utilizadas para confecção artesanal, derivam de materiais naturais $\mathrm{e}$ industrializados. Os elementos naturais originam-se do próprio ambiente de vivência e trabalho das participantes. Podemos destacar aqui, as diferentes qualidades de sementes, galhos de árvores, palha de milho, cascas de ovos, pedras e musgos. Os demais materiais utilizados, provém de objetos industrializados adquiridos por meio de compras pessoais ou doações de terceiros. Podendo citar como exemplo, as caixas de papelão, garrafas Pet, jornal, retalhos de tecido entre outros. Como resultado da união desses materiais podemos destacar uma rica produção artesanal de cestaria em jornal, cerâmica fria, decoupagem, serigrafia, pinturas em MDF, chaveiros em tecidos, tapeçaria com malha entre outros como destacam as fotografias abaixo.

Figura 4 - Produção de bonecas confeccionadas com retalhos de tecido e palha de milho. Assentamento Pinheiro Machado, município de Pinheiro Machado/RS. 
Negretto, C., \& Silva, M. A. (2018). Problematizando o trabalho invisivel das mulheres e a divisão sexual de trabalho no campo: uma parceria entre educação popular e feminismo...

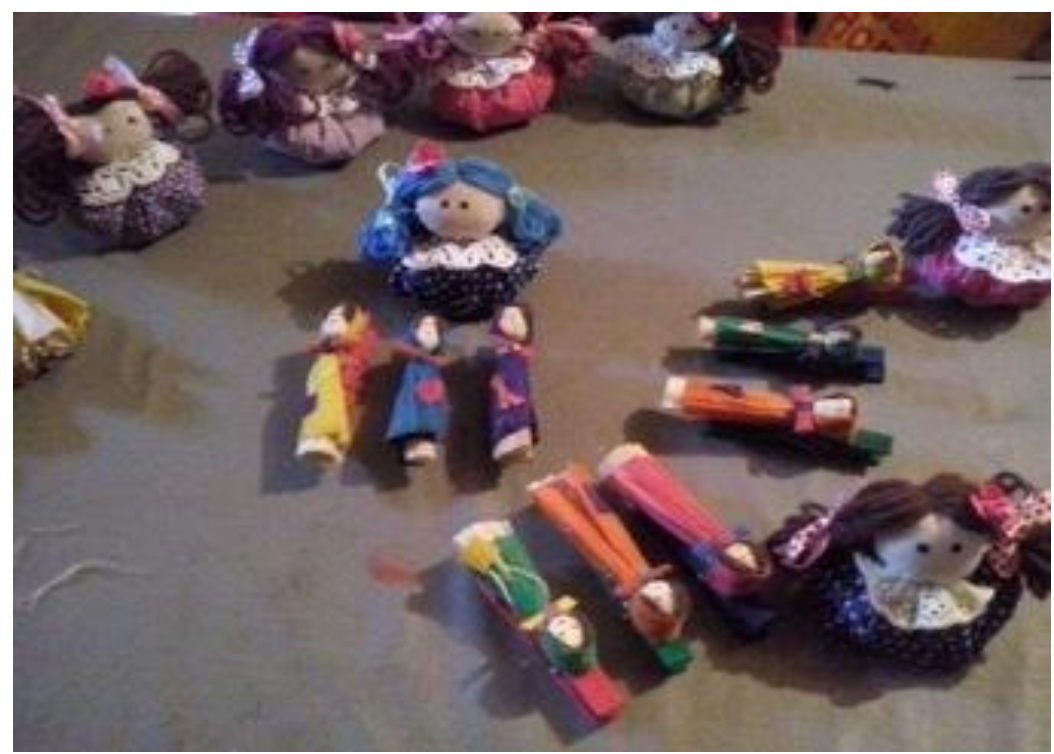

Fonte: do projeto, jul., 2015.

Figura 5 - Artesanatos produzidos durante as oficinas do projeto. Caixas de MDF, decoradas com mosaicos de cascas de ovos.

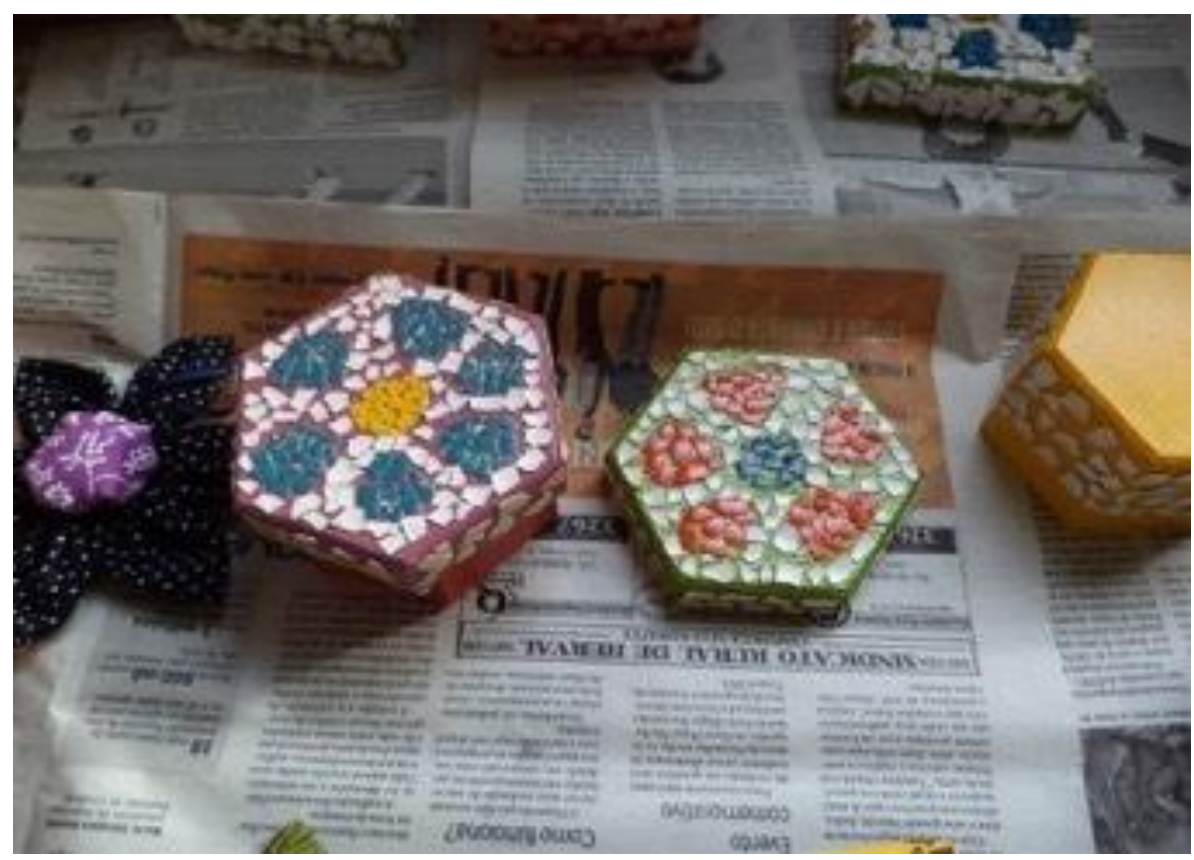

Fonte: Projeto de extensão Trabalho Artesanal com Mulheres do Movimento dos Trabalhadores rurais sem Terra (MST).

Os produtos confeccionados geralmente são vendidos na feira da Reforma Agrária que acontece duas vezes por mês no centro da cidade de Pinheiro Machado/RS. O incentivo à produção artesanal se constitui como uma forma 
alternativa de incentivo às economias de base local, assegurando a preservação da cultura regional, bem como a geração de renda para inúmeras famílias, considerando que grande parte das mulheres encontra no artesanato uma segunda condição de garantir a manutenção do bem-estar de seus familiares (Lemos, 2011).

Figura 6 - Feira da Reforma Agrária, município de Pinheiro Machado/RS.

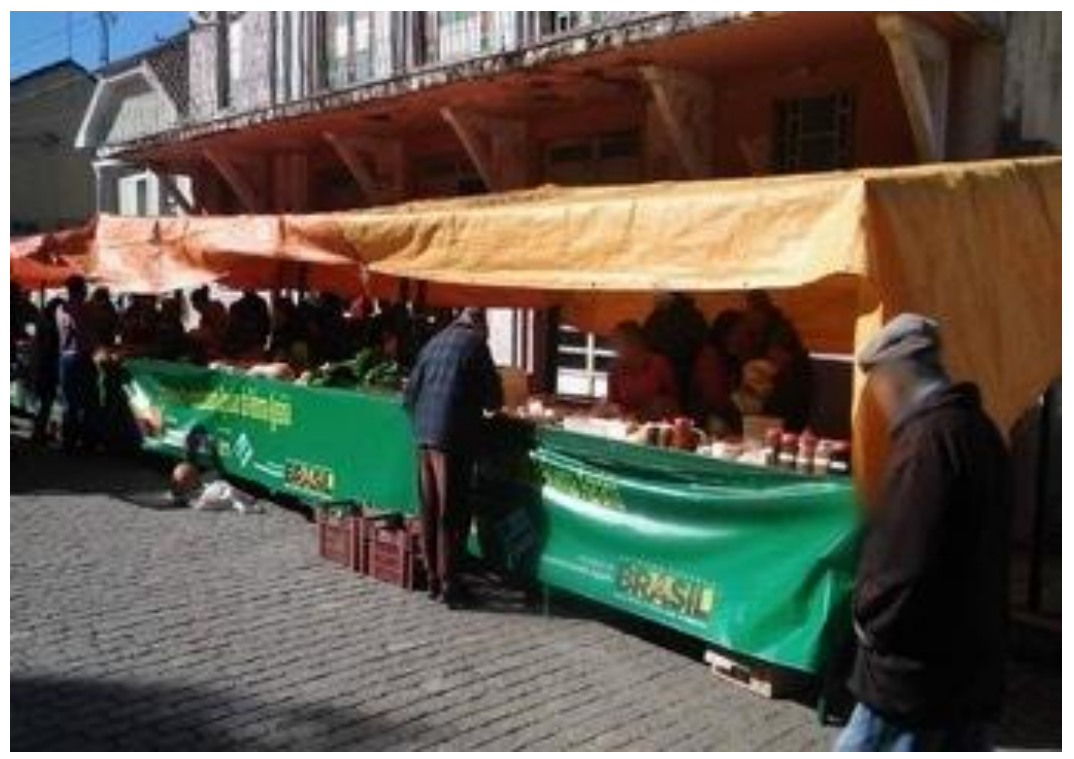

Fonte: da pesquisa, ago., 2017.

O estimulo à produção artesanal influi diferentes extensões da vida da mulher camponesa, desenvolvendo a criatividade, a coordenação motora, auxiliando no controle da ansiedade, aumentando o poder de concentração, além de fornecer a imensa satisfação em cada mulher de se verem capazes de produzir peças lindas com as próprias mãos. Esses momentos coletivos possibilitam trocas de experiências e fortalecem cada participante enquanto mulher e enquanto grupo.

De acordo com as observações e registro dos relatos coletados, a socialização e amizade vinham se extinguindo entre elas em decorrência dos afazeres domésticos que, por vezes, sucumbe horas do dia, tornando-se um trabalho repetitivo e fastidioso, não remanescendo tempo para empenhar-se em incumbências contrárias. $\mathrm{O}$ incentivo à participação nos encontros reaproximou essas mulheres, auxiliando-as para um novo e melhor convívio social, se configurando, similarmente, no fortalecimento da autoestima, desenvolvimento da cidadania e estimulo da emancipação feminina pelo direito de instruírem-se e serem protagonistas de sua própria história. 
Figura 7 - Grupo de mulheres do Assentamento Santa Inácia em um momento de socialização e amizade.

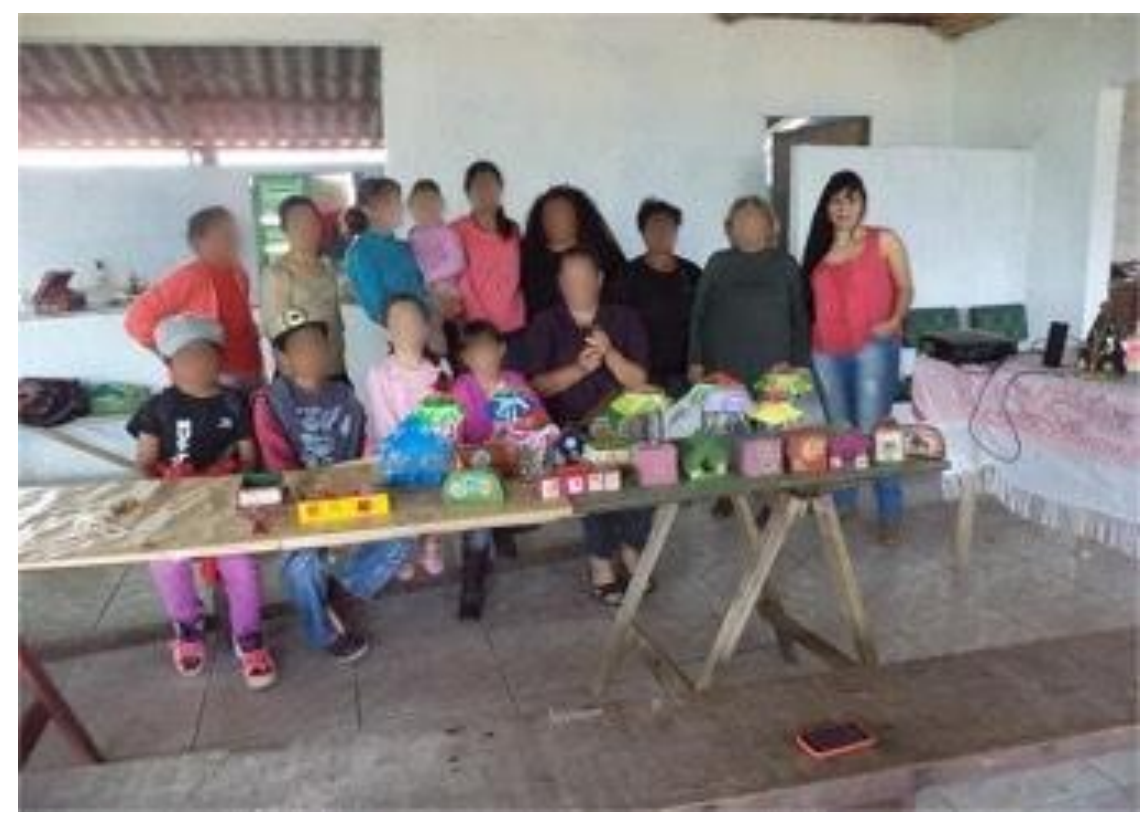

Fonte: Acervo do Projeto, 2015.

\section{Resultados e discussão: A problematização do trabalho feminino}

Pesquisar questões de gênero no meio rural, sobretudo no contexto do cotidiano da mulher da reforma agrária, nos possibilita conhecer a realidade dos assentamentos não unicamente sob enfoque socioeconômico, mas também nas relações sociais estabelecidas do dia a dia que, além de dividirem tarefas e lugares sexualmente desiguais, acarretam em desvalorização, exploração, servidão, reclusão, e silenciamento feminino.

$\mathrm{Na}$ divisão sexual do trabalho no campo, cabe a elas (99\% das mulheres) a produção de alimentos para o consumo da família, através de pomares e a reprodução de pequenos animais. De acordo com Korol (2016) “As mulheres da América Latina são responsáveis por $90 \%$ da produção de alimentos da agricultura familiar e tem participação ativa nas atividades relacionadas ao processamento, preservação e comercialização desses produtos". Porém, a jornada de trabalho da mulher rural é subestimada pelo fato do seu trabalho agrícola ser considerado uma extensão do trabalho doméstico (p. 96).

Conforme as observações de campo, as atividades desempenhadas por muitas mulheres camponesas, são em sua grande maioria, tríplices em relação às atividades realizadas pelos homens. São elas, que primeiramente despertam no alvorecer do dia, ordenham as vacas, aprontam o 
desjejum, desadormecem e preparam as crianças para a escola e executam rapidamente o serviço doméstico antes de destinar-se ao companheiro nas atividades do lote. Na metade do dia, é ela que, mesmo cansada da lavragem, prepara o almoço e se encarrega das demais atividades domésticas que ficaram para trás. No intervalo da tarde, reassume as atividades do lote, regressando para casa somente no final do dia para efetuar as mesmas tarefas de ordem reprodutivas relacionadas ao cuidado da casa e dos filhos.

Os dados coletados pela pesquisa, mostram que do ano de 2014 até 2016, 90\% das 40 mulheres camponesas declaram não se identificarem como trabalhadoras, sobretudo porque realizam tarefas secundárias em relação aos produtos economicamente mais importantes para a conformação da renda familiar. Ainda que seu trabalho cotidiano inclua a elaboração de produtos que são vendidos nas feiras e geram receitas para a propriedade, seja não transformados, como ovos, pequenos animais ou verduras; seja artesanais, ou panificados como pães, doces e conservas, raramente elas consideravam essas tarefas como trabalho remunerado. Isso porque, no processo da construção do modelo patriarcal, a mulher quando expulsa do universo econômico que cria o produto excedente, cumpriu uma função econômica fundamental. A de restaurar a força de trabalho que move a economia, ficando desse modo, marginalizada da esfera pública e escondida atrás da fachada da família monogâmica até os dias atuais. Para Hirata e Kergoat (2007), esse trabalho além de ser invisível, é realizado de forma gratuita pelas mulheres "não para elas mesmas, mas para outros, e sempre em nome da natureza, do amor e do dever materno" ( $p$. 597).

A ideia de que o trabalho masculino é mais prestigiado que o feminino é outro fator a ser questionado. Esse conceito é tão reproduzido que leva até as próprias mulheres acreditarem que são incapazes de ser reconhecidas e valorizadas por algo que venham a fazer. Essa forma particular de pensar a divisão social do trabalho é problematizado por Hirata \& Kergoat (2007) em, “dois princípios organizadores: o princípio de separação (existem trabalhos de homens e trabalhos de mulheres) e o princípio hierárquico (um trabalho de homem "vale" mais que um trabalho de mulher" (p. 599). Uma das principais justificativas para essa ideologia é o processo da naturalização da desigualdade, que rebaixa o sexo biológico e o reduz as construções e as práticas sociais. 
Pelo menos $30 \%$ das mulheres pesquisadas, denunciaram à ideologia de naturalização de 'papéis sociais' sexuados e desiguais. Essas, tem que lidar diariamente com a exclusão da vida pública e desvalorização do seu trabalho, seja ele executado no meio rural, na esfera domiciliar, no cuidado dos filhos ou na "ajuda" prestada ao marido, de modo que não significa uma simples tarefa realizada esporadicamente; essa ajuda significa que muitas trabalham lado a lado, diretamente com o companheiro na lavoura desempenhando as mesmas funções, porém não são reconhecidas pelo trabalho realizado, não participam das decisões sobre os rendimentos do produto final $\mathrm{e}$ não recebem retorno igualitário na execução das tarefas de ordem doméstica. Essa desigualdade de direitos e deveres, não apenas as decepciona mas também afeta sua qualidade de vida, já que muitas se queixam regularmente de dores musculares em razão do excesso de trabalho.

Para a pequena parcela de mulheres que consegue tomar consciência da servidão desvalorização e exploração da força de trabalho à que estão submetidas, existe à denúncia de que a maternidade cria condições que impedem a participação feminina na vida pública. Segundo Saffioti (1987), o desprestigio feminino na vida pública, a desvalorização e a exploração do trabalho feminino "decorre de sua capacidade de ser mãe", isto é, “a sociedade tenta fazer crer que é natural que a mulher se dedique aos afazeres domésticos, aí compreendida a socialização dos filhos, como é natural sua capacidade de dar à luz" (p. 09). Essa construção é delimitada com bastante precisão segundo o modelo de organização social vigente, e pode ser comprovado de acordo com os relatos das participantes:

Lá em casa, sempre me ensinaram que serviço doméstico era coisa da mulher fazer (Assentada C, 2013).

Eu sempre como comida fria. Todo mundo senta à mesa e ergue o prato pra cima pra mim servir um por um, cortar a carne a salada, servir o suco. Quando me sento, a comida já esfriou e todos já terminaram de comer. Fico sozinha na mesa (Assentada C, 2015).

Meu marido diz que serviço doméstico é coisa de mulherzinha, por isso não posso nem pensar em ensinar meus filhos a cozinhar, quanto mais a lavar a louça, fazer algum serviço na casa (Assentada C, 2016).

Para Silvia Federici (2017), essa depreciação do trabalho realizado pelas mulheres, se inicia com o processo de privatização da terra na Europa e nas Américas e a chegada das relações monetárias em meados do século XVII. Nesse novo período que se iniciou, as 
mulheres

encontraram

maiores

"dificuldades do que os homens para se sustentar, tendo sido confinadas ao trabalho reprodutivo no exato momento em que este trabalho estava sendo absolutamente desvalorizado" (p. 145). Se para "classe alta era a propriedade que dava ao marido poder sobre sua esposa e filhos, nas classes baixas a exclusão das mulheres do recebimento de salário dava aos trabalhadores um poder semelhante, aí entendido como o patriarcado do salário" (p. 194).

Para a realidade da mulher camponesa, as consequências históricas do modelo social patriarcal tem um peso ainda maior, isso porque, se pararmos para olhar, o homem camponês não trabalha na indústria, portanto ele não depende de um salário mínimo para sobreviver. É a mulher que lado a lado, trabalha com ele na lavoura garantindo a subsistência familiar. Cabe perguntar, por que então, se destaca na organização da família camponesa um falso patriarcado do salário? Por que cabe às mulheres a função de "ajudantes" e não o mesmo título que eles de 'trabalhadoras rurais'.

Na perspectiva de Federici (2017), há uma resposta para essa construção de inferioridade e subordinação da mulher ao homem, "Na medida em que o corpo feminino foi apropriado pelo estado e pelos homens, foi também forçado a funcionar como um meio para reprodução e acumulação de trabalho" (p. 34). A desigualdade social e de gênero é resultado de uma sociedade de lutas de classes historicamente construída.

Diante desse contexto, algumas reflexões se fazem latentes a respeito da participação e da representação dos papéis sociais interpretados pelo homem e pela mulher rural nos espaços de decisão, na divisão sexual do trabalho e nas implicações que rebatem na temática de gênero. $O$ engajamento coletivo com pautas centralizadas e objetivas que busquem superar a disparidade entre os sexos, possibilitará o enfrentamento da opressão e da desigualdade. A participação e a voz das mulheres nos espaços de decisão e formação, encontra-se como uma perspectiva de firmamento para a transformação de uma nova realidade social.

A organização de espaços de formação, tendo o respaldo no pensamento social e filosófico dos estudos feministas e na Educação Popular vem auxiliando a luta das mulheres camponesas em todas as suas ações, de vida e trabalho. Problematizar a luta das mulheres camponesas pelo viés da educação popular pode ser definida como uma forma de educar transformadora, que liberta o ser humano, atuando contra os 
efeitos de uma psicologia da opressão, contribuindo para a humanização de uma sociedade menos injusta, menos iníqua, menos castradora.

\section{Considerações finais}

A partir desta pesquisa, pode-se concluir que as mulheres ligadas aos quatro assentamentos buscam, através de suas ações organizativas e na prática cotidiana, é conquistar espaços que lhes foi historicamente retirado e serem reconhecidas pelo trabalho realizado, conforme relata uma assentada: "Queria ser mais valorizada como esposa, como artesã e agricultora. Queria que me respeitassem mais" (Assentada M, 2016). A luta pela igualdade nas relações sociais de trabalho, apresenta-se como um processo de melhoramento das relações de gênero e de evolução na história. No contexto histórico, a produção capitalista deslocou a mulher de seu espaço, como se ela fosse um mero objeto de reprodução e restringiu seu trabalho à esfera doméstica. Problematizar a luta feminista pelo viés da educação popular, tendo nos relatos das histórias de vida um fio condutor para compreender a realidade social, pode ser definido como uma forma transformadora de educar. Se há desejo de desconstruir os processos de desigualdade e injustiça é necessário superar os modelos sociais antigos e encarar um novo papel social: o de restaurador da humanidade dentro da sociedade. O enfrentamento da opressão, do anonimato político, social e econômico diz respeito a todas as mulheres e homens que querem torna-se sujeitos de direito a partir de um direito que se comporte de modo diferente do que está imposto. A importância do estudo e da pesquisa sobre as temáticas das relações de gênero em espaços informais, atende a perspectiva de uma educação voltada para as classes populares. E pode ser definida como uma educação transformadora, que liberta o ser humano, atuando contra os efeitos de uma psicologia da opressão, contribuindo para humanização de uma sociedade menos injusta, menos iníqua e menos castradora. 
Figura 8 - Grupo de mulheres, assentamento Pinheiro Machado, município de Pinheiro Machado/RS.

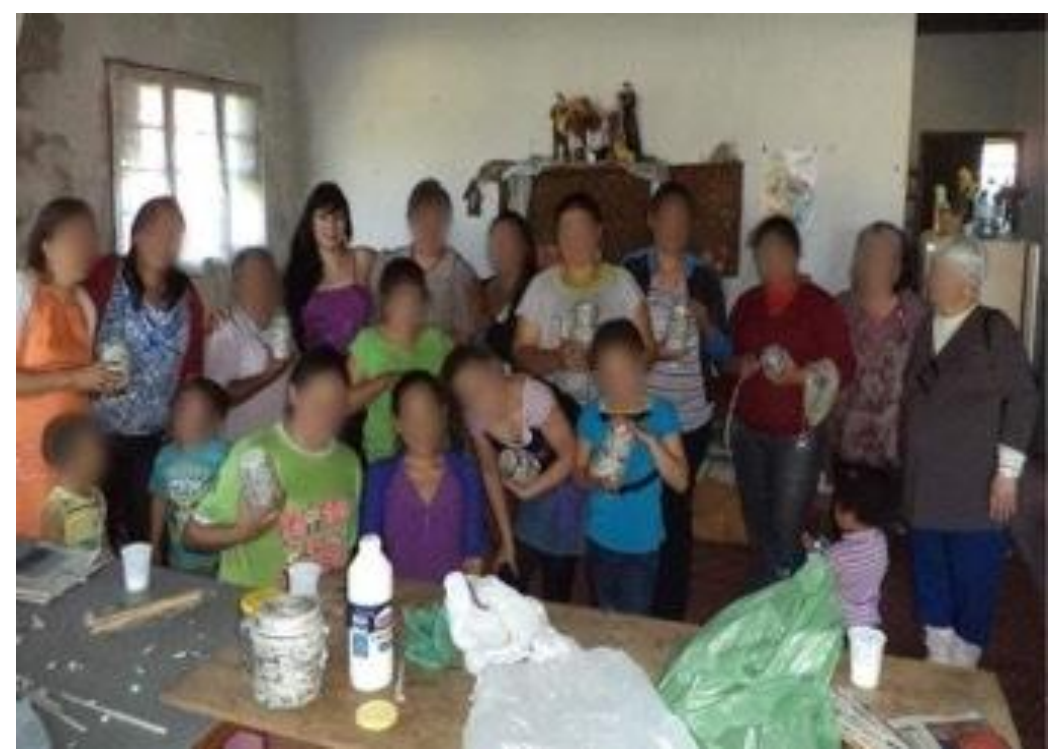

Fonte: do projeto, out., 2014.

\section{Referências}

Federici, S. (2017). Calibã e a bruxa: mulheres, corpo e acumulação primitiva. São Paulo: Elefante.

Freire, P. (1987). Pedagogia do oprimido, 17a. ed. Rio de Janeiro, Paz e Terra.

Hirata, H., \& Kergoat, D. (2007). Novas configurações da divisão sexual do trabalho. Cadernos de Pesquisa, 37(132), 595-609.

Korol, C. (2016). Somos tierra, semilla, rebeldia: Mujeres, tierra y territorios en América Latina. Fundación IntermonOxfam. Coedición: GRAIN.

Lemos, M. E. S. (2011). O artesanato como alternativa de trabalho e renda. (Dissertação de Mestrado). Universidade Federal do Ceará, Fortaleza, Ceará.

Negretto, C., Silva, M. A. (2017). Artesanato e MST: Uma libertação possível. In Anais do I Encontro
Internacional em Ciências Humanas (p. 2208-2218). Pelotas, RS.

Saffioti, H. I. B. (1987). O poder do macho. São Paulo: Moderna.

Vieira, V., \& Charf, C. (2012). Mulheres $e$ homens trabalhando pela paz e contra a violência doméstica. São Paulo: Associação Mulheres pela Paz.

Informações do artigo / Article Information

Recebido em : 31/05/2018

Aprovado em: 10/07/2018

Publicado em: 23/12/2018

Received on May 31th, 2018

Accepted on July 10th, 2018

Published on December 23th, 2018

Contribuições no artigo: As autoras foram responsáveis pela elaboração, análise e interpretação dos dados; escrita e revisão do conteúdo do artigo, e aprovação da versão final publicada.

Author Contributions: The authors were responsible for the designing, delineating, analyzing and interpreting the data, production of the manuscript, critical revision of the content and approval of the final version published. 
Negretto, C., \& Silva, M. A. (2018). Problematizando o trabalho invisivel das mulheres e a divisão sexual de trabalho no campo: uma parceria entre educação popular e feminismo...

Conflitos de interesse: As autoras declararam não haver nenhum conflito de interesse referente a este artigo.

Conflict of Interest: None reported.

Orcid

Carla Negretto

(iD) http://orcid.org/0000-0002-1950-2452

Márcia Alves da Silva

(iD) http://orcid.org/0000-0002-4727-2623

\section{Como citar este artigo / How to cite this article}

APA

Negretto, C., \& Silva, M. A. (2018). Problematizando o trabalho invisível das mulheres e a divisão sexual de trabalho no campo: uma parceria entre educação popular e feminismo. Rev. Bras. Educ. Camp., 3(4), 1184-1201. DOI: $\quad$ http://dx.doi.org/10.20873/uft.2525-

$\underline{4863.2018 \mathrm{v} 3 \mathrm{n} 4 \mathrm{p} 1184}$

ABNT

NEGRETTO, C.; SILVA, M. A. Problematizando o trabalho invisível das mulheres e a divisão sexual de trabalho no campo: uma parceria entre educação popular e feminismo.

Rev. Bras. Educ. Camp., Tocantinópolis, v. 3, n. 4, set./dez., p. 1184-1201, $2018 . \quad$ DOI: http://dx.doi.org/10.20873/uft.2525-4863.2018v3n4p1184 